\title{
Synthesis and Evaluation of the Ability of Poly(Methacrylic Acid-co-acrylamide)/nanoclay Composite Hydrogel in the Adsorption of Methylene Blue Dye
}

Hamid Safarzadeh

University of Tehran

Seyed Jamaleddin Peighambardoust ( $\mathbf{j}$ j.peighambardoust@tabrizu.ac.ir)

University of Tabriz https://orcid.org/0000-0001-7514-4445

Seyed Hamed Mousavi

University of Tehran

Reza Mohammadi

University of Tabriz

Rauf Foroutan

University of Tabriz

Seyed Hadi Peighambardoust

University of Tabriz

\section{Research Article}

Keywords: Methacrylic acid-co-acrylamide copolymer, Hydrogel, Nanocomposite, Adsorption capacity, Aqueous solutions

Posted Date: November 22nd, 2021

DOI: https://doi.org/10.21203/rs.3.rs-1071501/v1

License: (c) (1) This work is licensed under a Creative Commons Attribution 4.0 International License. Read Full License 


\title{
Synthesis and evaluation of the ability of poly(methacrylic acid-co- acrylamide)/nanoclay composite hydrogel in the adsorption of methylene blue dye
}

\author{
Hamid Safarzadeh ${ }^{1}$, Seyed Jamaleddin Peighambardoust ${ }^{2}$, Seyed Hamed Mousavi ${ }^{1}$, Reza Mohammadi ${ }^{3}$, Rauf \\ Foroutan $^{2}$, Seyed Hadi Peighambardoust ${ }^{4}$ \\ ${ }^{1}$ Separation Processes \& Nanotechnology Lab, Faculty of Caspian, College of Engineering, University of Tehran, \\ Tehran, Iran \\ ${ }^{2}$ Faculty of Chemical and Petroleum Engineering, University of Tabriz, Tabriz, 5166616471, Iran, \\ ${ }^{3}$ Polymer Research Laboratory, Faculty of Chemistry, University of Tabriz, Tabriz, Iran \\ ${ }^{3}$ Department of Food Science, College of Agriculture, University of Tabriz, Tabriz 5166616471, Iran \\ ${ }^{*}$ Corresponding author email: j.peighambardoust@tabrizu.ac.ir
}

\section{Abstract}

The performance of poly(methacrylic acid-co-acrylamide/nanoclay composite (poly(MAA-coAAm)/NCC) hydrogel to adsorb methylene blue (MB) dye from aqueous solutions was investigated and the adsorption efficiency was improved by incorporating Cloisite 30B nanoclays in the adsorbent structure. The hydrogels were analyzed using FTIR, XRD, TGA, and SEM analysis. The effect of adsorbent dose, temperature, initial dye concentration, contact time, and $\mathrm{pH}$ on the efficiency of the adsorption process was investigated. Adsorption efficiencies of 98.57 and $97.65 \%$ were obtained for poly(MAA-co-AAm)/NCC and poly(MAA-co-AAm) hydrogels, respectively. Kinetic study revealed that the adsorption process followed pseudo-first-order kinetic model and $\alpha$-parameter values of 6.558 and $1.113 \mathrm{mg} / \mathrm{g}$.min were obtained for poly(MAA-co-AAm)/NCC and poly(MAA-co-AAm) hydrogels, respectively indicating a higher ability of nanocomposite hydrogel in adsorbing MB-dye. In addition, the results of the intra-particle diffusion model showed that various mechanisms such as intra-particle diffusion and liquid film penetration are important in the adsorption. The Gibbs free energy parameter of adsorption process showed negative values of -256.52 and $-84.071 \mathrm{~J} / \mathrm{mol} . \mathrm{K}$ for poly(MAA-co-AAm)/NCC and poly(MAA-co-AAm) hydrogels indicating spontaneous nature of the adsorption. The results of enthalpy and entropy showed that the adsorption process was exothermic and random collisions were reduced during the adsorption. The equilibrium data for the adsorption process using poly(MAA-co-AAm)/NCC and poly(MAA-co-AAm) hydrogels followed Freundlich and Langmuir isotherm models, respectively. The maximum adsorption capacity values of 32.83 and $21.92 \mathrm{mg} / \mathrm{g}$ were obtained for poly(MAA-co-AAm)/NCC and poly(MAA-coAAm) hydrogels, respectively. Higher adsorption capacity of nanocomposite hydrogel was attributed to the 
presence of Cloisite 30B clay nanoparticles in its structure. In addition, results of $\mathrm{R}_{\mathrm{L}}, \mathrm{n}$, and $\mathrm{E}$ parameters showed that the adsorption process was performed optimally and physically.

35 Keywords: Methacrylic acid-co-acrylamide copolymer, Hydrogel, Nanocomposite, Adsorption capacity, Aqueous solutions.

\section{Introduction}

Dyes are used as an important industrial raw material in many applications such as paper, textile and plastic industries [1]. The improper discharge of dye containing wastewater streams into the environment that can lead to many environmental problems [2]. In general, dyes can be classified into cationic, anionic, and nonionic categories [3]. Various studies have shown that among the various dyes used in industry, cationic dyes are more harmful because they easily bind to the cell cytoplasm $[4,5]$. Methylene blue (MB) is one of the synthetic cationic dyes that is extensively used in industries such as textile, paper, pesticides, cosmetics, and printing due to its high solubility and stability in water [6]. Prolonged exposure to MB dye can cause various diseases such as vomiting, nausea, anemia, hypertension, respiratory failure, eye damage, local burns, increased transpiration, and mental disorders [7]. Therefore, it is important to eliminate contaminants such as dyes from industrial wastewater streams.

However, the refining of industrial effluents containing dyes is very difficult due to the presence of complex compounds with poor biodegradation, high $\mathrm{pH}$ and turbidity [8]. Various methods have been proposed to eliminate contaminants from wastewaters, however, most of them possess disadvantages such as high operating and maintenance costs, low performance, and production of toxic sludge [9]. Surface adsorption method has received much attention by many researchers due to the advantages of easy performance, high efficiency, no secondary sludge production, and environmental friendliness [10]. Various adsorbents such as different types of clay soils, natural fibers, carbon nanotubes, polymeric materials, zeolites, active carbon, and magnetic composites have been used for dye removal from aqueous solutions [11]. Clay soils show a high potential to adsorb heavy metals and organic compounds due to their suitable photochemical properties such as multilayer structure, high surface area, and high cation exchange capacity. Among the clay soils used, expandable layer silicates such as montmorillonite (MMT) have been recognized and used as adsorbents [12]. MMT clay is one of the low-cost adsorbents with a high cation exchange 
capacity, which has the ability to absorb cationic pollutants due to high negative charges. Cloisite 30B is a natural MMT clay whose surface is modified by quaternary ammonium salts [13].

Polymeric hydrogels have received much attention due to their advantages such as ease of preparation, high tendency to absorb water, high porosity, ease of operation, and diverse morphology [14]. Hydrophilic cross-linked polymers that form a three-dimensional network with the ability to absorb large amounts of water and aqueous fluids form hydrogels [15]. These hydrogel adsorbents respond to process conditions such as $\mathrm{pH}$, redox, ionic strength, light, electric field, etc. $[16,17]$. In the adsorption process, the hydrogels absorb contaminants to their surface until they are saturated. After the complete saturation of hydrogels, they can be disposed of as agricultural fertilizer or compost due to their biodegradability [18]. Among the hydrogels used in the adsorption process, those produced based on poly(methacrylic acid) show good absorption properties due to inclusion of many functional groups in their structure. These functional groups provide active centers for the adsorption of dye molecules upon swelling of the hydrogel system [19].

In the present study, it was hypothesized that fabricating nanocomposite hydrogels using Cloisite 30B clay nanoparticles could increase the efficiency of the adsorbent to remove MB-dye. Thus, poly(methacrylic acid-co-acrylamide/nanoclay composite (PMAc-co-Ac/NCC) hydrogels were synthesized and characterized. Moreover, the effect of clay concentration, $\mathrm{pH}$, temperature, contact time, adsorbent dose, and initial MB dye concentration on the efficiency of the adsorption process was investigated. After determining the optimal value of the desired parameters, thermodynamic, equilibrium, and kinetic studies of the process were examined.

\section{Materials and Methods}

\subsection{Materials}

Methacrylic acid (MAA) with a MW of $86.06 \mathrm{~g} / \mathrm{mol}$, acrylamide (AAm) with a MW of 71.08 $\mathrm{g} / \mathrm{mol}$, and N,N' methylene bis-acrylamide with a MW of $154.17 \mathrm{~g} / \mathrm{mol}$, potassium persulfate were obtained from Merck (Darmstadt, Germany). Cloisite 30B nanoclay powder was obtained from Southern Clay Co. (Austin, TX, USA). All chemicals prepared from the suppliers were pure and analytical grade.

\subsection{Synthesis of poly(MAA-co-AAm) and poly(MAA-co-AAm)/NCC hydrogels}


91 Firstly, $2 \mathrm{~g}$ of acrylamide (AAm) monomer was dissolved in $10 \mathrm{~mL}$ of distilled to get a 92 homogenous solution. Then, $0.02 \mathrm{~g}$ of methylene bis-acrylamide as a cross-linker was poured to the above solution with magnetic stirring and the obtained mixture was added to the three-neck flask followed by addition of $4.8 \mathrm{~mL}$ of methacrylic acid (MAA) monomer under nitrogen atmosphere to remove oxygen from the reaction medium. Finally, $0.1 \mathrm{~g}$ of potassium persulfate was added as an initiator for free radical copolymerization reaction at a temperature of $70{ }^{\circ} \mathrm{C}$ under vigorous stirring (1200 rpm). The copolymerization reaction was completed in $2-5 \mathrm{~h}$ depending on the monomer concentration. After the reaction was completed, the poly(MAA-co-AAm) hydrogel was dried and pulverized. The method of preparation of poly(MAA-co-AAm)/NCC hydrogel followed the same procedure as explained for poly(MAA-co-AAm) hydrogel except that after the preparation MAA monomer solution, a suitable amount of Cloisite 30B nanoclay was added and the solution was sonicated for 40-60 min to form a homogenous mixture.

\subsection{Swelling of hydrogels}

Swelling is an important characteristic of a hydrogel system affecting its adsorption performance [20]. In the present study, the effect of Cloisite 30B nanoclay concentration on the swelling value 106 of the nanocomposite hydrogels was investigated. To measure swelling per cent, $0.2 \mathrm{~g}$ of hydrogel with different nanoclay concentrations was dispersed in distilled water $(50 \mathrm{~mL})$ at room temperature and kept stirred overnight. Then, the hydrogels were separated from the aqueous medium and the swelling per cent was calculated using Eq 1.

110 Swelling $(\%)=\frac{\left(W_{s}-\mathrm{W}_{i}\right)}{W_{i}} \times 100$

where $\mathrm{W}_{\mathrm{s}}$ and $\mathrm{W}_{\mathrm{i}}$ are the weights of swollen and initial hydrogels, respectively.

\subsection{Adsorption study of hydrogels}

113 The adsorption of MB dye using two types of hydrogels was studied. The effect of various 114 parameters such as monomers (AAm to MAA) ratio, nanoclay concentration, temperature, 115 adsorbent dose, initial $\mathrm{pH}$, contact time, and initial MB dye concentration on the adsorption process 116 efficiency was evaluated. To investigate the effect of initial $\mathrm{pH}$ on the efficiency of the adsorption 117 process, the initial $\mathrm{pH}$ in the range of 3-10 was evaluated at constant experimental conditions such 118 as temperature of $25^{\circ} \mathrm{C}$, contact time of $60 \mathrm{~min}$, adsorbent dose of $1.5 \mathrm{~g} / \mathrm{L}, \mathrm{MB}$ dye concentration 
119

120

121

122

123

124

$125 q_{t}=\frac{\left(C_{i}-\mathrm{C}_{e}\right) V}{m}$

where $C_{\mathrm{i}}$ and $C_{\mathrm{e}}$ are the initial and final concentration of MB dye $(\mathrm{g} / \mathrm{L}), V$ is the volume of the

of $10 \mathrm{mg} / \mathrm{L}$ and mixing speed of $500 \mathrm{rpm}$. When the optimal $\mathrm{pH}$ was determined, other parameters such as temperature $\left(25-50^{\circ} \mathrm{C}\right)$, contact time $(10-250 \mathrm{~min})$, adsorbent dose $(0.5-4 \mathrm{~g} / \mathrm{L})$ and the initial concentration of dye $(10-100 \mathrm{mg} / \mathrm{L})$ at the specified optimum $\mathrm{pH}$ were examined. The adsorbent was then separated from the aqueous solution and the percentage of MB-dye adsorption $(\mathrm{R})$ and adsorbent adsorption capacity $\left(\mathrm{q}_{\mathrm{e}}\right)$ were determined using the following Eqs:

$R(\%)=\frac{\left(C_{i}-\mathrm{C}_{e}\right)}{C_{i}} \times 100$ solution used (L), and $m$ is amount of dry adsorbent used (g).

\section{Results and discussion}

\subsection{Properties of hydrogel adsorbents}

\subsubsection{FTIR analysis}

Fourier-transform infrared (FTIR) is a useful technique to specify chemical structures and possible interactions between the functional groups of constituents of a material [21]. FTIR spectra of Cloisite 30B nanoclay and both hydrogel adsorbents before and after the adsorption of MB dye are shown in Figure 1. Cloistite 30B nanoclay (Fig. 1a) exhibited characteristic peak at wavenumbers of $1045 \mathrm{~m}^{-1}$ and $462-725 \mathrm{~cm}^{-1}$ attributed to the vibrations of Si-O-Si bonds [22] and Si-O-Al functional groups [23]. Both hydrogel adsorbents before adsorption process (Fig. 1 b,c) showed characteristics peaks at $3400-3445 \mathrm{~cm}^{-1}$ attributing to vibrations of $-\mathrm{OH}$ and $-\mathrm{NH}$ bonds, 2853-2928 $\mathrm{cm}^{-1}$ assigning to vibrations of the C-H bonds, $1545 \mathrm{~cm}^{-1}$ indicating ester groups, 1640$1645 \mathrm{~cm}^{-1}$ ascribing to $-\mathrm{OH}$ bond vibrations or the interaction between carbonyl and vinyl groups, 450-965 $\mathrm{cm}^{-1}$ demonstrating low-intensity vibrations of $\mathrm{C}=\mathrm{O}, \mathrm{C}-\mathrm{C}, \mathrm{C}-\mathrm{O}$ bonds [24]. Hydrogel adsorbents after the adsorption process (Fig. $1 \mathrm{~d}, \mathrm{e}$ ) did not show large differences in their FTIR spectra, .only minor changes in the range and intensity of peaks in their structure was observed, which could indicate that the bond between the MB dye molecule and the adsorbents' surface is physical due to weak Van der Waals forces [25]. 


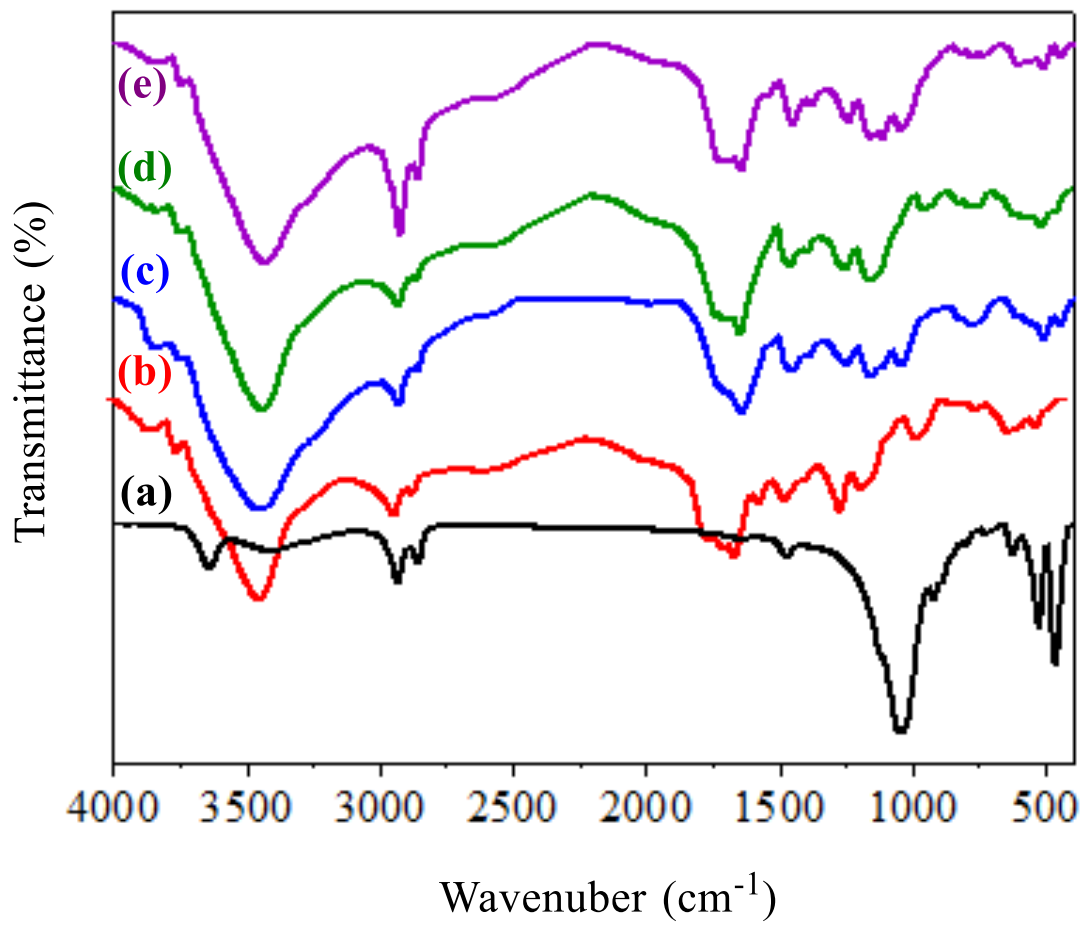

Fig. 1. FTIR spectra of (a) Cloisite 30B nanoclay, (b) poly(MAA-co-AAm) hydrogel before adsorption, (c) poly(MAA-co-AAm)/NCC hydrogel before adsorption, (d) poly(MAA-co-AAm) hydrogel after adsorption, (e) poly(MAA-co-AAm)/NCC hydrogel after adsorption.

\subsubsection{XRD analysis}

$\mathrm{X}$-ray diffraction (XRD) analysis can determine spacing distance or height in clay nanoparticles [26]. In this work, the XRD patterns of Cloisite 30B nanoclay and two types of adsorbents measured 2at $\theta$ range of $0.5-10^{\circ}$ are shown in Figure 2a. As the results show, a peak is observed in the structure of Cloisite $30 \mathrm{~B}$ at $2 \theta$ of $4.25^{\circ}$ indicating the crystalline phase (001) in its structure. The distance between the crystalline phases and clay galleries in the Cloisite $30 \mathrm{~B}\left(\mathrm{~d}_{001}\right)$ determined using Bragg's law $\left(\mathrm{n} \lambda=2 \mathrm{~d}_{001} \sin \theta\right)$ was $1.94 \mathrm{~nm}$. After the placement of Cloisite $30 \mathrm{~B}$ in the structure of poly(MAA-co-AAm)/NCC hydrogel the peak of the 001-crystalline phase was completely disappeared, indicating that the silicate layers in the structure of the nanocomposite hydrogel had no accumulation. This also indicated that the polymer chains have been successfully placed between the Cloisite 30B composite silicate layers and exfoliated structure of nanocomposite has been performed successfully [27].

\subsubsection{TGA analysis}



177 improved.

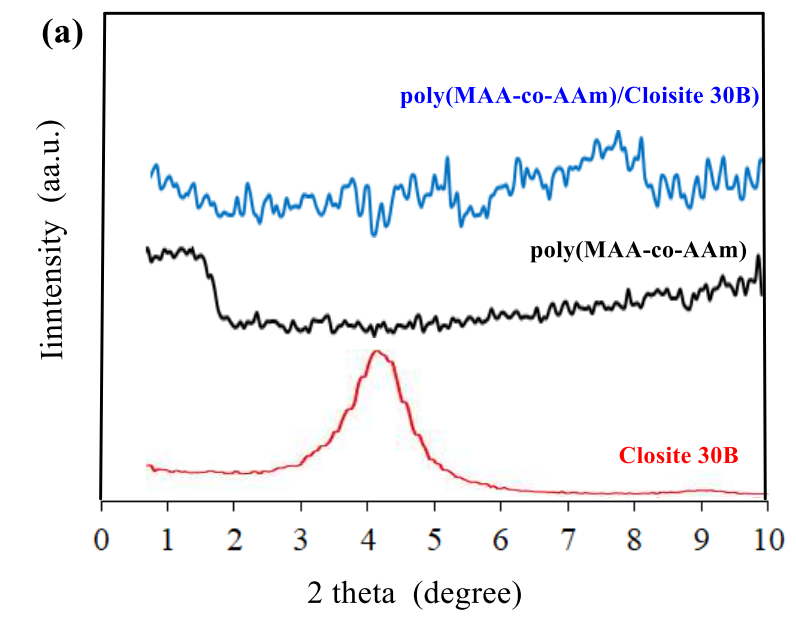

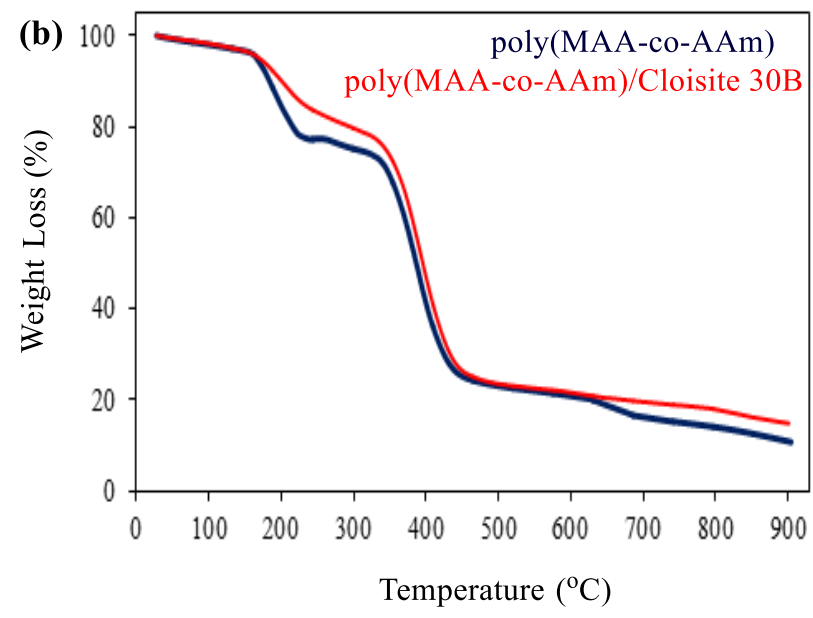

178

179 180 181 182 183

Thermogravimetric analysis (TGA) is a technique to assess thermal stability of compounds by recording their weight loss as function of increasing temperature [28]. In this study, TGA was performed at a temperature range of $20-900^{\circ} \mathrm{C}$. Fig. $2 \mathrm{~b}$ shows TGA thermograms of both types of adsorbents. An initial weight loss as function of moisture evaporation occurred at $100-150{ }^{\circ} \mathrm{C}$. The second weight of about $20 \%$ was seen at $150-300^{\circ} \mathrm{C}$ probably relating to degradation of acrylamide as well as hydrogel bonds [29]. The main characteristic peaks at this temperature range appeared at $196^{\circ} \mathrm{C}$ for poly(MAA-co-AAm) hydrogel and $201^{\circ} \mathrm{C}$ for poly(MAA-co-AAm)/NCC hydrogels. The degradation at $350-450^{\circ} \mathrm{C}$ was possibly related to the destruction of $\mathrm{C}-\mathrm{H}$ bonds in methacrylic acid [30] structure, in which the hydrogels lost about $50 \%$ of their initial weight. The major characteristic peaks at this temperature range appeared at a $388{ }^{\circ} \mathrm{C}$ for poly(MAA-co-AAm) hydrogel and $399{ }^{\circ} \mathrm{C}$ for poly(MAA-co-AAm)/NCC hydrogel. The final degradation stage occurred at $600-700{ }^{\circ} \mathrm{C}$ indicating the successful formation of a hydrogel. A total weight loss of $85-89 \%$ was observed from temperature of 20 to $900{ }^{\circ} \mathrm{C}$. TGA results also indicated that the degradation of poly(MAA-co-AAm) hydrogel had a sharp slope compared to the poly(MAA-coAAm)/NCC hydrogel which implies that the thermal stability of nanocomposite hydrogel was

Fig. 2. a) X-ray diffraction (XRD) and b) thermo-gravimetric analysis (TGA) results of Cloisite 30B, poly(MAA-coAAm), and poly(MAA-co-AAm)/NCC hydrogels

\subsubsection{SEM results}

SEM analysis was used to evaluate the surface morphology hydrogel samples before and after MB dye adsorption [31]. According to SEM results, Cloisite 30B nanoclay (Fig. 3a) showed a layered 
structure that was in parallel with XRD results (Fig. 2a). Poly(MAA-co-AAm) hydrogel (Fig 3b) exhibited smooth surface while poly(MAA-co-AAm)/NCC hydrogel (Fig. 3c) showed rather rough surface with small grooves and pores that might be due to inclusion clay nanoparticles in the structure of the nanocomposite hydrogel. After the adsorption process of MB dye using the adsorbents, extensive changes were observed in the surface of the adsorbents indicating that the pores and grooves on the surface were covered, which could be due to the adsorption and placement of MB dye molecules on the surface of the adsorbents (Fig. 3d, e).
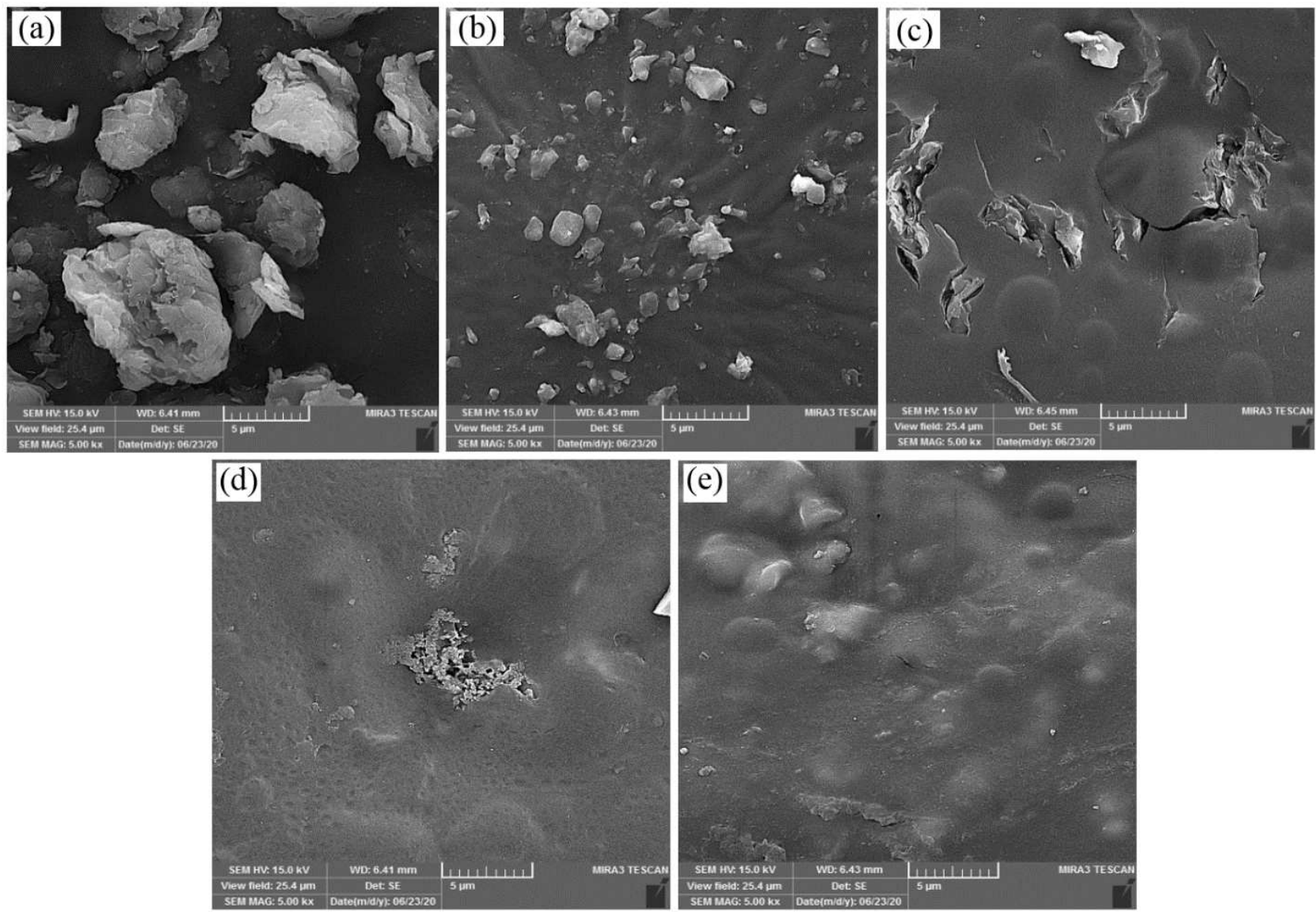

Figure 3. SEM images of a) Cloisite 30B nanoclay, b) poly(MAA-co-AAm) hydrogel before dye adsorption, c) poly(MAA-co-AAm)/NCC hydrogel before dye adsorption, (d) poly(MAA-co-AAm)/NCC hydrogel after dye adsorption and (e) poly(MAA-co-AAm) hydrogel after dye adsorption 
Reaction coefficients of monomers $\left(r_{1}\right.$ and $\left.r_{2}\right)$ is a suitable criterion to evaluate the active presence of monomers in the copolymerization process. When the reaction coefficient of one monomer is higher than that of another monomer, the placement of the monomers in the copolymer structure will be random [32]. In the present study, the activity coefficients for MMA and AAm monomers were found to be 1.94 and 0.30 , respectively, indicating a higher activity of MMA compared to AAm, and therefore, indicating its stronger contribution in the structure of the synthesized copolymer. To optimize the effect of MMA and AAm monomers on the efficiency of MB-dye adsorption, copolymers with MMA: AAm ratios of 1:2, 1:1 and 2:1 were synthesized and their effect on adsorption maximum efficiency was evaluated in experimental conditions $(\mathrm{pH}=8$, temperature $=25^{\circ} \mathrm{C}$, adsorbent dose $=1.5 \mathrm{~g} / \mathrm{L}$, contact time $=60 \mathrm{~min}$, initial dye concentration $=$ $10 \mathrm{mg} / \mathrm{L}$, and mixing speed $=500 \mathrm{rpm}$ ). Result showed that copolymers with MMA: AAm ratios of 1:2, 1:1 and 2:1 gave maximum efficiencies of 43.7, 83.4 and 93.5\%, respectively. Thus, synthesized nanocomposite hydrogel adsorbent with MMA: AAm ratio of 2:1 provided the highest adsorption efficiency.

\subsubsection{The effect of Cloisite $30 \mathrm{~B}$ clay weight percent, adsorbent dose and pH}

Effect of Cloisite 30B weight percent on swelling and adsorption efficiency of the poly(MAA-coAAm)/NCC hydrogel adsorbent was investigated. As can be seen from Fig. 4a increasing weight percent of clay nanoparticles up to $10 \%$ wt. increased swelling and adsorption efficiency of adsorbent. This might be related to involvement of more hydrophilic groups in the structure of nanoclay composite (NCC) adsorbent due to the presence of clay nanoparticles. Moreover, SEM analysis (Fig. 3c) of NCC adsorbent exhibited rough surface with small grooves and pores, which could imply for its increased swelling and adsorption. Weight concentration of $10 \%$ was found to be an optimum amount of nanoclay incorporation and concentrations more than $10 \%$ wt. decreased swelling and adsorption efficiency again. This can be probably explained by the fact that at higher concentration clay nanoparticles becomes accumulated among copolymer chains in the formed hydrogel system, which reduces the penetration of MB-dyes molecules in NCC adsorbent structure [5].

Fig. $4 \mathrm{~b}$ demonstrates the effect of adsorbent dose at concentration of $0.5-4 \mathrm{~g} / \mathrm{L}$ on adsorption efficiency of NCC adsorbent. Increasing adsorbent dose from 0.5 to $4 \mathrm{~g} / \mathrm{L}$ increased adsorption efficiency from 79 to $96 \%$ for poly(MAA-co-AAm) hydrogel and 87 to $99 \%$ for poly(MAA-co- 
227 AAm)/NCC hydrogel. This can be explained by possible increased number of unsaturated active 228 sites providing sufficient surface area for MB-dye adsorption as a result of increased adsorbent 229 does [3]. In addition, adsorbent dose of 1.5 - $2 \mathrm{~g} / \mathrm{L}$ was found to be an optimum dose to improved 230 adsorption efficiency, since no further increase was seen beyond this concentration.

231 Initial $\mathrm{pH}$ is regarded as an important factor of adsorption that can influence surface load and 232 thereby, functional groups' ionization degree on adsorbent surface [33, 34]. The effect of initial $233 \mathrm{pH}$ on the efficiency of MB-dye adsorption process using two types of hydrogel adsorbents is 234 shown in Fig. 4c. Increasing the initial pH from 3 to 8, significantly increased adsorption efficiency 235 of both adsorbents. A maximum efficiency was obtained at $\mathrm{pH}=8$. Alkaline $\mathrm{pHs}(\mathrm{pH}>8)$ did not 236 significantly increase adsorption efficiency. At acidic conditions $(\mathrm{pH}<5)$, the adsorption process 237 efficiency was low, which could be due to various factors such as 1) the competition among $\mathrm{H}^{+}$ 238 ions and MB-dye molecules to be located on the adsorbent surfaces, 2) high density positive 239 charges of adsorbent surface produce electrostatic repulsion forces between the surface and MB240 dye molecule [35]. Higher adsorption efficiency of adsorbents at pHs > 5 can be explained by 241 reduction of the density of $\mathrm{H}^{+}$charges on the adsorbent surface, which leads to initiation of 242 negative charge and increase in the number of deprotonated $\mathrm{COOH}$ groups at the adsorbent surface 243 [36], which can increase adsorption performnace. 

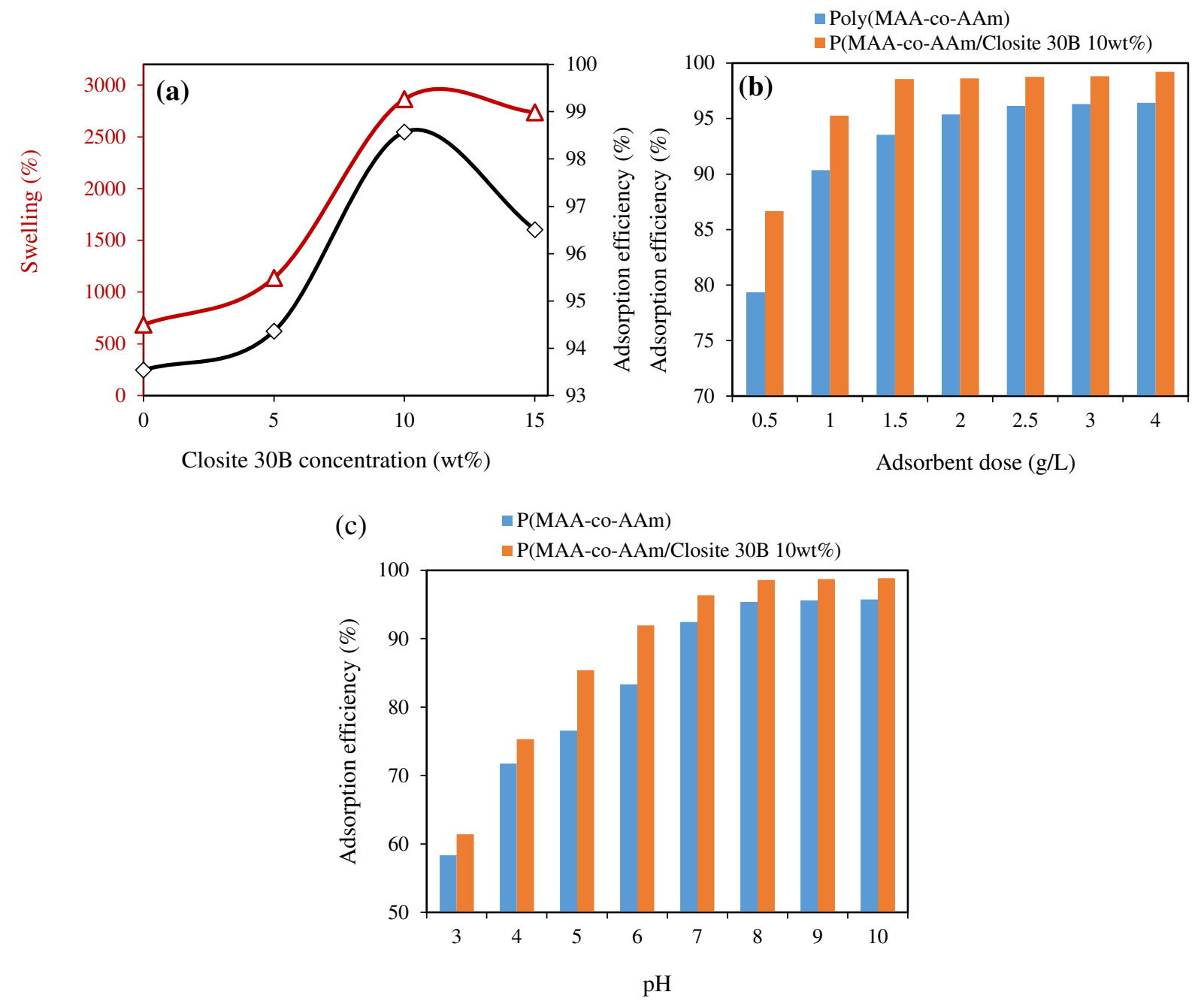

Figure 4. a) effect of Cloisite 30B clay concentration on swelling and adsorption efficiency of poly(MAA-coconcentration of $10 \mathrm{mg} / \mathrm{L}$, and mixing speed of $500 \mathrm{rpm}, \mathrm{b}$ ) effect of adsorbent dose on adsorption efficiency of both types of hydrogels, and c) effect of $\mathrm{pH}$ on adsorption efficiency of both types of hydrogels.

\subsubsection{Thermodynamic study and effect of temperature}

251 Fig. 5a shows temperature effect on the adsorption efficiency of both types of adsorbents. Heating 252 from 25 to $40{ }^{\circ} \mathrm{C}$ significantly decreased the efficiency of MB-dye adsorption. Thus, a temperature 253 of $25{ }^{\circ} \mathrm{C}$ was found as an optimum temperature for the adsorption process. This could be related 254 to exothermic nature of process that heating adversely affects the adsorption. To investigate 255 thermodynamic parameters such as enthalpy $\left(\Delta \mathrm{H}^{\circ}\right)$, entropy $\left(\Delta \mathrm{S}^{\circ}\right)$ and Gibbs free energy $\left(\Delta \mathrm{G}^{\circ}\right)$ 256 were calculated using Eqs. 4 and 5. 
$258 \ln \mathrm{K}_{\mathrm{D}}=\frac{-\Delta \mathrm{H}^{\circ}}{\mathrm{R} \mathrm{T}}+\frac{\Delta \mathrm{S}^{\circ}}{\mathrm{R}}$

259 Where $\mathrm{R}$ is the universal gas constant, $\mathrm{T}$ is the absolute temperature $(\mathrm{K}), \mathrm{K}_{\mathrm{D}}$ is the equilibrium 260 constant $\left(K_{D}=C_{A} / C_{e}\right), C_{A}$ and $C_{e}$ are the concentration of MB-dye adsorbed and the concentration 261 of dye remained after adsorption.

262 The linear relationship of $\ln K_{\mathrm{D}}$ vs. $1 / \mathrm{T}$ for the determination of thermodynamic parameters is 263 shown in Fig. 5b and the thermodynamic parameters determined for the MB-dye adsorption 264 process is presented in Table 1 . The negative values were obtained for $\Delta \mathrm{G}^{\circ}$ using both types of 265 adsorbents indicating that the adsorption process is considered as spontaneous and desirable. $\Delta \mathrm{H}^{\circ}$ 266 values of poly(MAA-co-AAm) hydrogel and poly(MAA-co-AAm)/NCC hydrogel were -84.071 $267 \mathrm{~kJ} / \mathrm{mo}$ and $-106.153 \mathrm{~kJ} / \mathrm{mol}$, respectively, indicating that the adsorption is exothermic [37] 268 emphasizing on role of temperature in the process. In addition, negative values were obtained for $269 \Delta \mathrm{S}^{\circ}$ parameter, which indicates that the collisions between the MB-dye molecules with the 270 adsorbent surface are not random and the random collisions were decreased during the adsorption 271 process.

272
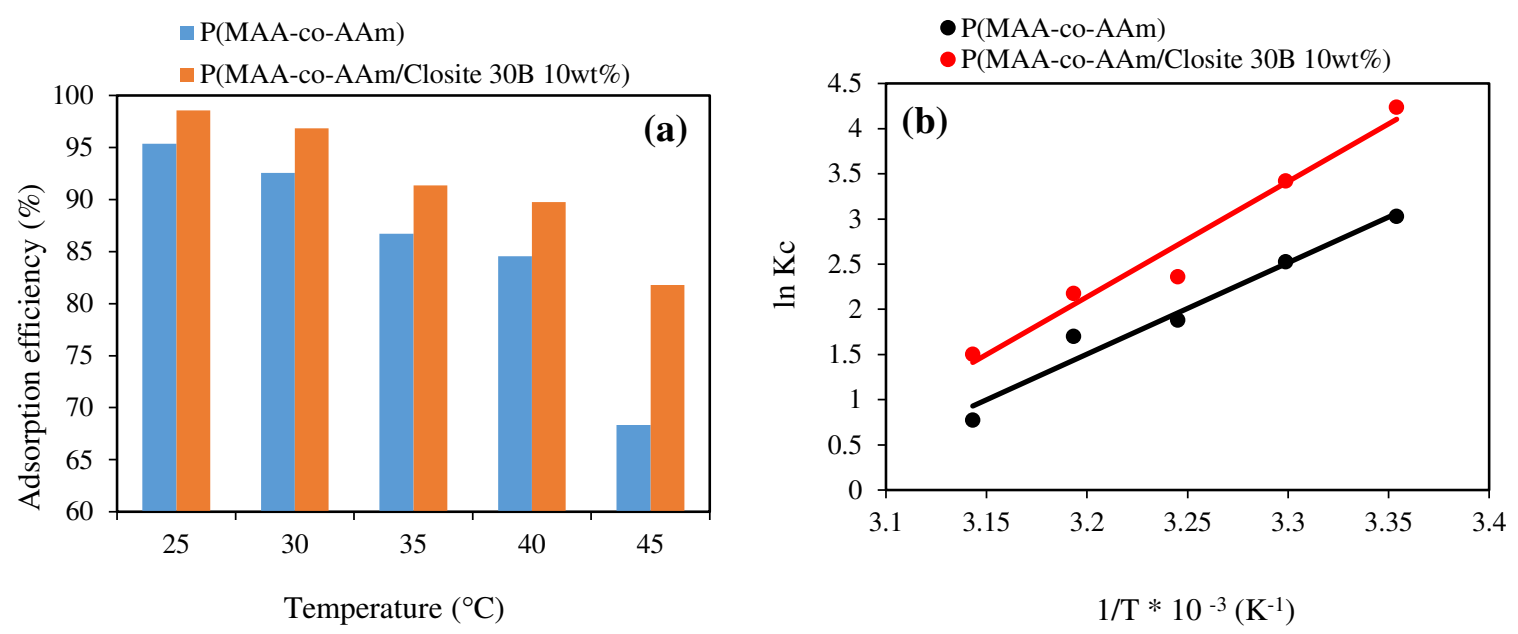

274 Figure 5. a) the effect of temperature on the efficiency of the adsorption process (at optimal adsorbent dose, initial $\mathrm{pH}$ of 8 , dye concentration of $10 \mathrm{mg} / \mathrm{L}$, contact time of $60 \mathrm{~min}$, and mixing speed of $500 \mathrm{rpm}$ ), and b) linear relationship of Van-t-Hoff for determination of thermodynamic parameters 
Table 1. Thermodynamic parameters for MB-dye adsorption process using two types of adsorbents

\begin{tabular}{|c|c|c|c|c|}
\hline Adsorbent & $\mathbf{T}\left({ }^{\circ} \mathbf{C}\right)$ & $\Delta \mathbf{G}^{\circ}(\mathbf{K J} / \mathbf{m o l})$ & $\Delta \mathbf{H}^{\circ}(\mathbf{K J} / \mathbf{m o l})$ & $\Delta \mathbf{S}^{\circ}(\mathbf{J} / \mathbf{m o l} . \mathbf{K})$ \\
\hline \multirow{5}{*}{ Poly(MAA-co-AAm) Hydrogel } & 25 & -7.504 & \multirow{5}{*}{-84.071} & \multirow{5}{*}{-256.52} \\
\hline & 30 & -6.353 & & \\
\hline & 35 & -4.805 & & \\
\hline & 40 & -4.425 & & \\
\hline & 45 & -2.035 & & \\
\hline \multirow{5}{*}{ Poly(MAA-co-AAm/NCC (10 \% wt.) Hydrogel } & 25 & -10.493 & \multirow{5}{*}{-106.153} & \multirow{5}{*}{-321.934} \\
\hline & 30 & -8.617 & & \\
\hline & 35 & -6.038 & & \\
\hline & 40 & -5.651 & & \\
\hline & 45 & -3.969 & & \\
\hline
\end{tabular}

278 292 [40]:

293 Pseudo - First - Order : $\quad \mathrm{q}_{t}=\mathrm{q}_{e}\left(1-\mathrm{e}^{-\mathrm{k}_{1} t}\right)$

294 Pseudo - First - Order : $\quad \mathrm{q}_{t}=\frac{k_{2} \mathrm{q}_{e}^{2} \mathrm{t}}{1+\mathrm{k}_{2} \mathrm{q}_{e} \mathrm{t}}$

295

\subsubsection{Kinetic study and the effect of time}

Equilibrium contact time is an important factor in economic wastewater treatment systems [38]. Rapid absorption of contaminants (such as heavy metals) and equilibrium in a short period of time indicates the effectiveness of the adsorbent used in the wastewater treatment process [39]. Fig. 6a demonstrates the effect of contact time (10 - $250 \mathrm{~min})$ on the efficiency of the adsorption process. Increasing contact up to $80 \mathrm{~min}$ increased the adsorption efficiency followed by a reduction after $80 \mathrm{~min}$. The increase in the efficiency of the adsorption process by increasing contact time can be due to the presence of sufficient surface and empty active sites for the placement of MB-dye molecules. After $80 \mathrm{~min}$, the adsorption process reached an equilibrium.

Kinetic behavior is an important parameter that controls the amount of contaminant adsorption and the time of adsorption process. Kinetic behavior of MB-dye adsorption using two types of adsorbents was studied in time range of 10 - 250 min. Pseudo-first-order (PFO), pseudo-secondorder (PSO), Elovich and intra-particle diffusion kinetic models were used according to Eqs. 6 - 8 
296 Where $\mathrm{q}_{\mathrm{t}}$ and $\mathrm{q}_{\mathrm{e}}$ are dye adsorption capacity per grams of dry adsorbent determined from 297 experimental results and kinetic models $(\mathrm{mg} / \mathrm{g}), \mathrm{k}_{1}$ is the constant rate of adsorption $\left(\mathrm{min}^{-1}\right), \mathrm{k}_{2}$ is the constant rate of pseudo-second-order kinetic model (g/mg.min), $\alpha$ is the initial absorbance 299 (mg/g.min), and $\beta$ is the desorption constant $(\mathrm{g} / \mathrm{mg})$.

300 Nonlinear relationship of PFO, PSO and Elovich kinetic models for MB-dye adsorption process 301 using both types of adsorbents (at $10 \%$ wt. of clay nanoparticles) are shown in Fig. 6b, c and the 302 variables determined using these models are reported in Table 2. Results showed that the kinetic 303 behavior of the adsorption process followed the PFO model, since this model provides a higher 304 correlation coefficient compared to other models and its root-mean-square error (RMSE) is lower. 305 The PFO kinetic model showed that chemical reactions do not play an effective role in the MB306 dye adsorption process. In addition, a parameters for poly(MAA-co-AAm) hydrogel and 307 poly(MAA-co-AAm/NCC hydrogel were determined to be 1.113 and $6.558 \mathrm{mg} / \mathrm{g} \cdot \mathrm{min}$, 308 respectively indicating the higher performance of NCC adsorbent to adsorb MB-dye [41].

309 The intra-particle diffusion model assumes that the capacity of dye adsorption changes with the 310 expression $\mathrm{t}^{1 / 2}$, which has been used in previous research to study the kinetics of the adsorption 311 [42]. The linear relationship of the intra-particle diffusion model is shown in Eq. 9:

312 Intra-particle Diffusion : $\mathrm{q}_{t}=\mathrm{K}_{\mathrm{int}} \sqrt{t}+\mathrm{I}$

313 Where $\mathrm{K}_{\mathrm{int}}\left(\mathrm{mg} / \mathrm{g} \cdot \mathrm{min}^{1 / 2}\right)$ is the parameter of intra-particle diffusion rate, which is determined from 314 the slope of the $\mathrm{q}_{\mathrm{t}}$ diagram vs. $\mathrm{t}^{1 / 2}$ (Fig. 6d). According to this model, if the $\mathrm{q}_{\mathrm{t}}$ plot vs. $\mathrm{t}^{1 / 2}$ is a 315 straight line, the intra-particle diffusion is the limiting step in the adsorption process, and if the 316 plot is not a straight line, the liquid film diffusion is the limiting adsorption process [43]. The 317 constants and correlation coefficient $\left(\mathrm{R}^{2}\right)$ of the intra-particle diffusion model are reported in Table 318 2. According to Fig. $6 \mathrm{~d}$, the $\mathrm{q}_{\mathrm{t}}$ versus $\mathrm{t}^{1 / 2}$ diagram for the MB-dye adsorption process is not a 319 straight line, indicating that the adsorption process using these adsorbents is complicated process 320 and includes adsorption and intra-particle diffusion [48]. 

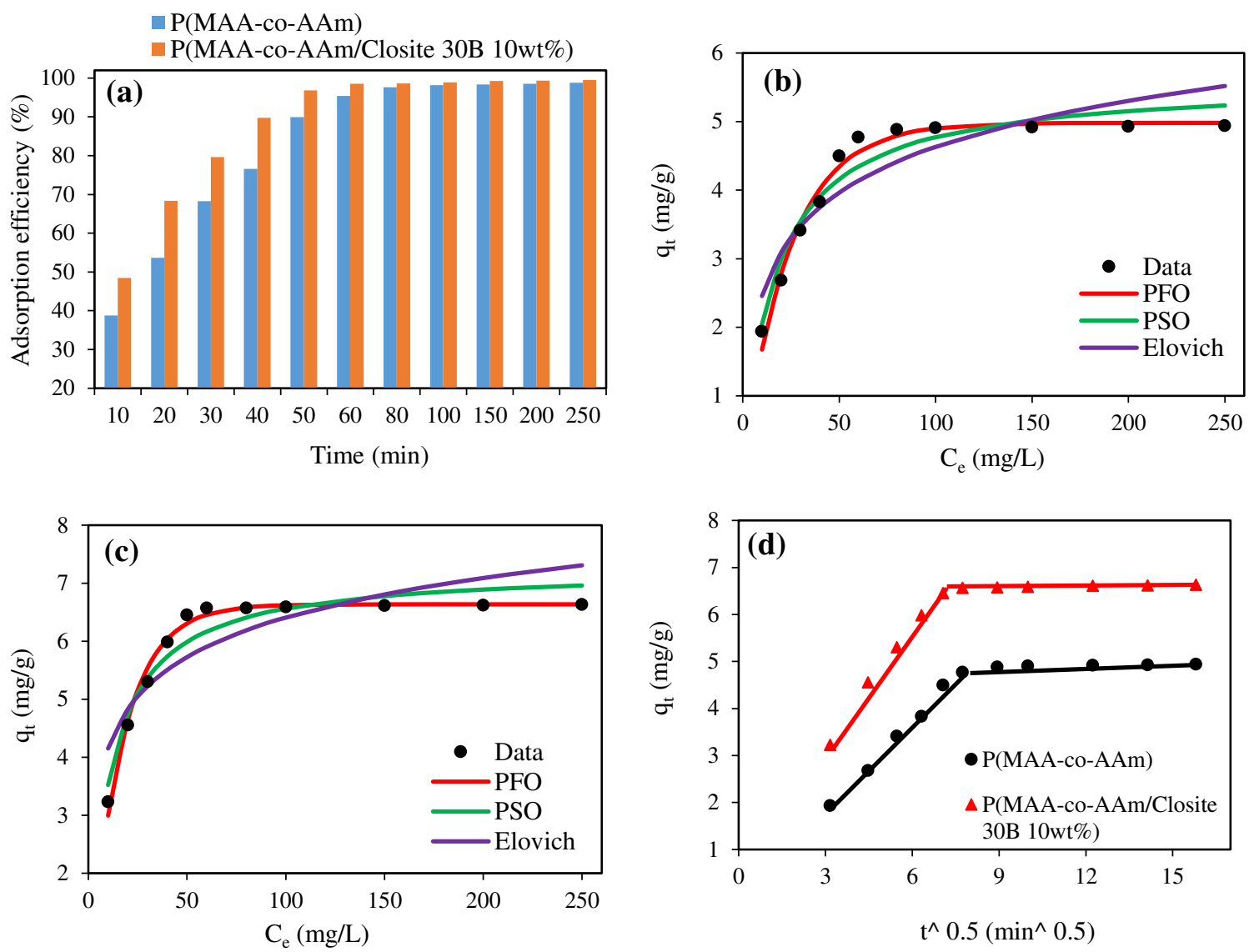

323 Figure 6. a) effect of contact time on the efficiency of the adsorption process (at optimal adsorbent dose, initial $\mathrm{pH}$ 324 of 8 , temperature of $25^{\circ} \mathrm{C}$, dye concentration of $10 \mathrm{mg} / \mathrm{L}$, mixing speed of $500 \mathrm{rpm}$ ), b, c) nonlinear relationship of kinetic models for MV-dye adsorption process using two types of adsorbents (containing $10 \%$ wt. of clay nanoparticles), and d) linear relationship for intra-particle diffusion model Table 2. Kinetics constants and variables determined for adsorption process using both adsorbents

Kinetic model

Pseudo-first order Model

qe cal
$\mathrm{K}_{1}$
$\mathrm{R}^{2}$

RMSE

Pseudo-second order Model

qe.cal
$\mathrm{K}_{2}$
$\mathrm{R}^{2}$

RMSE
Poly(MAA-co-AAm) hydrogel

Poly(MAA-co-AAm)/NCC hydrogel 


$\begin{array}{ccc}\text { Elovich equation } & \\ \alpha(\mathrm{mg} / \mathrm{g} \cdot \mathrm{min}) & 1.113 & 6.558 \\ \beta(\mathrm{g} / \mathrm{mg}) & 1.025 & 1.015 \\ \mathrm{R}^{2} & 0.8277 & 0.7588 \\ \mathrm{RMSE} & 0.4612 & 0.58\end{array}$

Intraparticle diffusion Model

$\begin{array}{ccc}\mathrm{K}_{\mathrm{i}, 1}\left(\mathrm{mg} / \mathrm{g} \cdot \mathrm{min}^{1 / 2}\right) & 0.6332 & 0.8222 \\ \mathrm{I}_{1}(\mathrm{mg} / \mathrm{g}) & 0.0929 & 0.7474 \\ \mathrm{R}^{2} & 0.9955 & 0.9928 \\ \mathrm{~K}_{\mathrm{i}, 2}\left(\mathrm{mg} / \mathrm{g} \cdot \mathrm{min}^{1 / 2}\right) & 0.0072 & 0.0082 \\ \mathrm{I}_{2}(\mathrm{mg} / \mathrm{g}) & 4.8261 & 6.5079 \\ \mathrm{R}^{2} & 0.915 & 0.9749\end{array}$

$329 \quad 3.2 .5$. Isotherm study and the effect of initial concentration of MB-dye

330 Fig. 7a shows the effect of the initial concentration of MB-dye in the range of 10-100 $\mathrm{mg} / \mathrm{L} \mathrm{on}$ 331 adsorption efficiency. A maximum adsorption efficiency (98.6\%) was obtained at dye 332 concentration of $10 \mathrm{mg} / \mathrm{L}$. Our results indicated that initial dye concentration is regarded as a 333 negative factor reducing the efficiency of the adsorption process. Increasing the dye concentration 334 led to decrease in adsorption efficiency. This is due to the fact that higher concentrations of dye 335 molecules either limit existing active sites on adsorbent molecules or increase electrostatic 336 repulsion forces between the adsorbent surface and MB-dye molecules [44].

337 In the adsorption process, the study of equilibrium concentration is an important and effective 338 parameter, because it shows the relationship between the adsorbed phase (contaminant) in the 339 aqueous solution and the adsorbent surface. To study the equilibrium behavior, different isotherm 340 models can be used. In the present study, the Langmuir, Friendlich and Dubinin-Radushkevich (D$341 \mathrm{R})$ isotherm models have been used. The nonlinear relationship of the isotherm models is shown 342 in Eqs. 10 - 12, respectively:

$343 \quad$ Langmuir : $\quad \mathrm{q}_{e}=\frac{q_{m} \mathrm{k}_{l} \mathrm{C}_{e}}{1+\mathrm{k}_{l} \mathrm{C}_{e}} \quad, \quad \mathrm{R}_{L}=\frac{1}{1+\mathrm{K}_{L}+\mathrm{C}_{o}}$

344 Freundlich : $\quad \mathrm{q}_{e}=\mathrm{k}_{f} \mathrm{C}_{e}^{\frac{1}{n}}$

345 Dubinin - Radushkevich : $\quad \mathrm{q}_{e}=\mathrm{q}_{m} \exp \left(-\beta \varepsilon^{2}\right), \quad \varepsilon=\mathrm{R} \mathrm{T} \ln \left(1+\frac{1}{C_{e}}\right)$ 
346 Where $\mathrm{q}_{\mathrm{e}}$ and $\mathrm{q}_{\mathrm{m}}$ are equilibrium and maximum adsorption capacities $(\mathrm{mg} / \mathrm{g})$, respectively, $\mathrm{K}_{\mathrm{L}}$ is

347 the Langmuir model constant, $\mathrm{k}_{\mathrm{f}}$ and $\mathrm{n}$ are the Freundlich model constants, $\mathrm{R}$ is the universal gas

348 constant, $\mathrm{T}(\mathrm{K})$ is the absolute temperature, $\varepsilon$ is the Polanyi coefficient, and $\beta$ is the activity 349 coefficient $\left(\mathrm{mol}^{2} / \mathrm{J}^{2}\right)$.

350 Fig. 7c and d show the nonlinear relationship of the isotherm models for the MB-dye adsorption 351 both types of adsorbents and the constants and variables determined for the adsorption process are 352 reported in Table 3. Based on results, the equilibrium data of the MB-dye adsorption using 353 poly(MAA-co-AAm) and poly(MAA-co-AAm/NCC followed the Langmuir and Freundlich 354 models, respectively (with higher $\mathrm{R}^{2}$ and lower RMSE).

355 Therefore, homogeneous and heterogeneous surfaces have an effective role in the adsorption 356 process. In addition, the value of $\mathrm{K}_{\mathrm{L}}$ parameter showed that the ability of poly(MAA-co357 AAm/NCC hydrogel was higher than that of poly(MAA-co-AAm) hydrogel in MB-dye 358 adsorption. The values of the $\mathrm{R}_{\mathrm{L}}$ and $\mathrm{n}$ parameters showed that the adsorption process is desirable. 359 The value of parameter $\varepsilon$ for MB-dye adsorption using poly(MAA-co-AAm) hydrogel and 360 poly(MAA-co-AAm/ gave values of 1.634 and $2.179 \mathrm{~kJ} / \mathrm{mol}$, respectively concluding that the 361 adsorption process is physical $(\varepsilon<8 \mathrm{~kJ} / \mathrm{mol})[10]$.
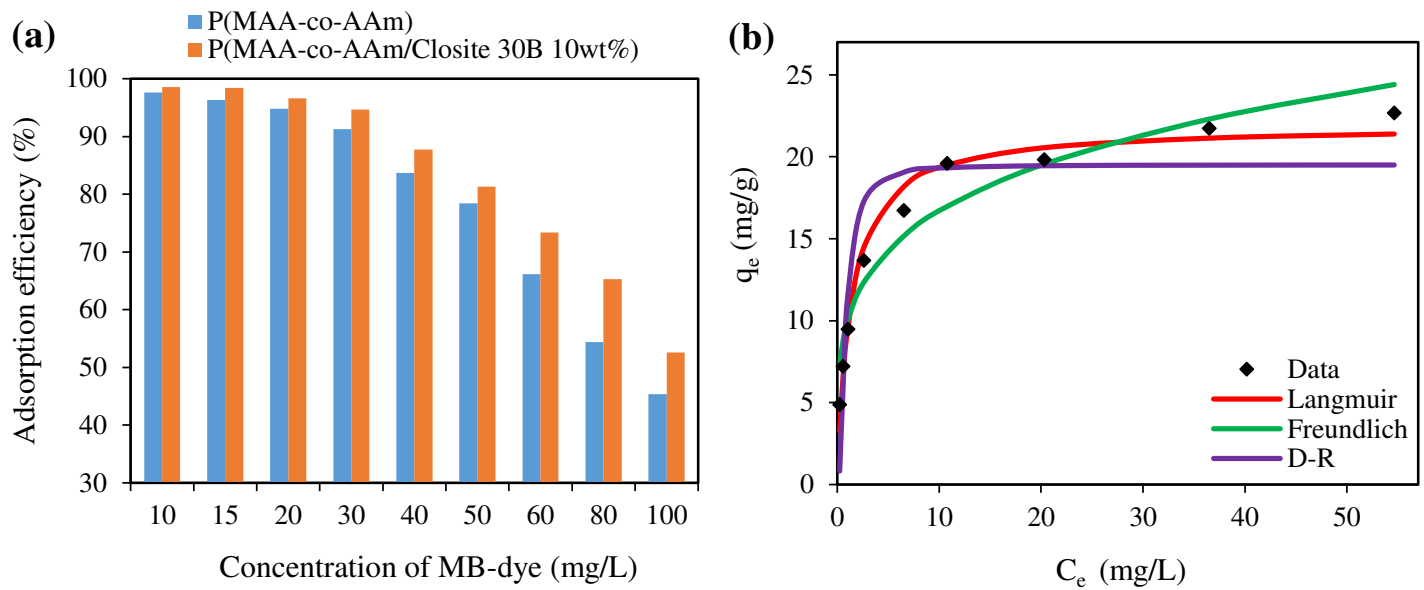


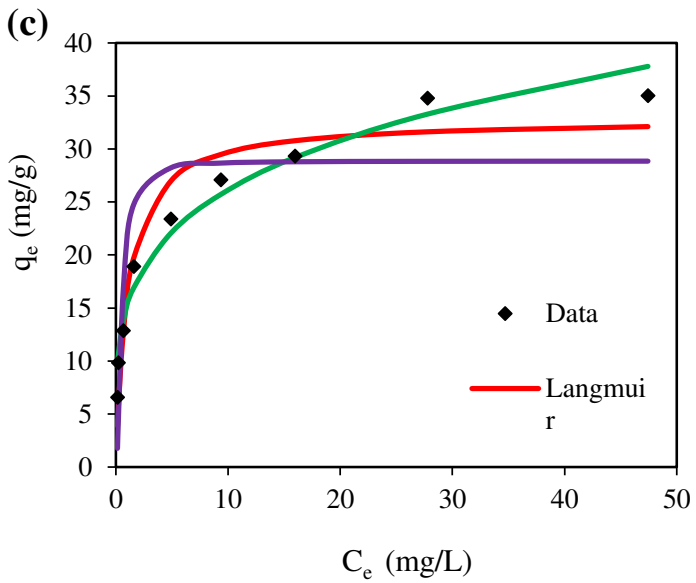

364 Figure 7. a) effect of MB-dye initial concentration on the adsorption efficiency (at optimal adsorbent dose, $\mathrm{pH}$ of 8 , 365 temperature of $25^{\circ} \mathrm{C}$, optimum contact time, mixing speed of $500 \mathrm{rpm}$ ), nonlinear relationship of isotherm models 366 for MB-dye adsorption process using b) poly(MAA-co-AAm) hydrogel and c) poly(MAA-co-AAm/NCC (10 \% wt Cloisite B)

Table 3. Constants and variables determined using isotherm models for MB dye adsorption process using the desired adsorbents

\begin{tabular}{|c|c|c|c|}
\hline Models & Parameters & Poly(MAA-co-AAm) hydrogel & $\begin{array}{c}\text { Poly(MAA-co-AAm)/NCC (10 } \\
\% \text { wt Cloisite B) hydrogel }\end{array}$ \\
\hline \multirow{5}{*}{ Langmuir } & $\mathrm{q}_{\mathrm{m}}(\mathrm{mg} / \mathrm{g})$ & 21.92 & 32.83 \\
\hline & $\mathrm{K}_{\mathrm{L}}(\mathrm{L} / \mathrm{mg})$ & 0.7443 & 0.9407 \\
\hline & $\mathrm{R}^{2}$ & 0.9752 & 0.9302 \\
\hline & $\mathrm{R}_{\mathrm{L}}$ & $0.013-0.118$ & $0.0105-0.096$ \\
\hline & RMSE & 1.11 & 2.986 \\
\hline \multirow{4}{*}{ Freundlich } & $\mathrm{n}$ & 4.462 & 4.216 \\
\hline & $\begin{array}{c}\mathrm{K}_{\mathrm{f}}(\mathrm{mg} / \mathrm{g} \\
\left.(\mathrm{L} / \mathrm{mg})^{1 / \mathrm{n}}\right)\end{array}$ & 9.96 & 15.13 \\
\hline & $\mathrm{R}^{2}$ & 0.9352 & 0.9687 \\
\hline & RMSE & 1.792 & 2 \\
\hline \multirow{5}{*}{$\begin{array}{l}\text { Dubinin-Radushkevich } \\
\text { (D-R) }\end{array}$} & $\mathrm{E}(\mathrm{KJ} / \mathrm{mol})$ & 1.634 & 2.179 \\
\hline & $\mathrm{q}_{\mathrm{m}}(\mathrm{mg} / \mathrm{g})$ & 19.51 & 28.86 \\
\hline & $\begin{array}{c}\beta \times 10^{-7} \\
\left(\mathrm{~mol}^{2} / \mathrm{J}^{2}\right)\end{array}$ & 1.872 & 1.053 \\
\hline & $\mathrm{R}^{2}$ & 0.8365 & 0.7759 \\
\hline & RMSE & 2.847 & 5.351 \\
\hline
\end{tabular}




\begin{tabular}{ccc}
\hline Adsorbent & MB dye & Reference \\
\hline MIL-101(Cr) & 22 & {$[45]$} \\
Wheat shells & 21.50 & {$[46,47]$} \\
CMC/kC/AMMT composite beads & 10.75 & {$[48]$} \\
Starch-based high-performance adsorptive hydrogel & 296.766 & {$[49]$} \\
N-isopropylacrylamide/itaconic acid/pumice composite & 22.18 & {$[50]$} \\
hydrogel & 24.10 & {$[51]$} \\
Poly(AMPS-co-IA) & 17.67 & {$[51]$} \\
P(NIPAAm/IA) & 36.25 & {$[52]$} \\
Activated lignin-chitosan composite extrudates & 58.24 & {$[53]$} \\
CMC/graphene oxide hydrogel & 21.92 & Present study \\
Poly(MAA-co-AAm) & 32.83 & Present study \\
\hline
\end{tabular}

\section{Conclusions}

375 In the present study, synthesized poly(MAA-co-AAm) and poly(MAA-co-AAm)/NCC hydrogels 376 by radical polymerization method was used to adsorb MB-dye. FTIR, TGA, XRD and SEM 377 analysis showed that the synthesized adsorbents were successfully developed and the silicate 378 layers of Cloisite 30B nanoclay were successfully placed between nanocomposite copolymeric 379 chains. Poly(MAA-co-AAm)/NCC hydrogels adsorbent exhibited superior adsorption efficiency 380 compared to poly(MAA-co-AAm hydrogel. Meanwhile such adsorbent had an advantage of 381 application at lower concentration dose using low contact time. Thermodynamic study revealed exothermic and spontaneous nature of adsorption process using both types of adsorbents. Also, the equilibrium behavior of poly(MAA-co-AAm) and poly(MAA-co-AAm)/NCC followed the

384 Langmuir and Freundlich models, respectively. The values of $\mathrm{R}_{\mathrm{L}}, \mathrm{n}$ and $\varepsilon$ parameters showed that 385 the adsorption process is desirable and physical. The kinetic behavior of the adsorption process 386 followed the pseudo-first-order kinetic model, which shows the low effect of chemical events in 387 the adsorption process. In addition, the intra-particle diffusion model showed that various mechanisms such as intra-particle diffusion and liquid film penetration are effective in the adsorption process. Therefore, based on the mentioned results, it can be stated that the use of

390 poly(MAA-co-AAm) and poly(MAA-co-AAm)/NCC hydrogels can be a promising method in 391 removing MB-dye from aqueous solutions and can be used to purifying dye containing aqueous 392 solutions. 


\section{References}

394 1. Gao M, Xu D, Gao Y, et al (2021) Mussel-inspired triple bionic adsorbent: Facile preparation of layered double hydroxide@ polydopamine@ metal-polyphenol networks and their selective adsorption of dyes in single and binary systems. J Hazard Mater 420:126609

2. Cao N, Zhao X, Gao M, et al (2021) Superior selective adsorption of MgO with abundant oxygen vacancies to removal and recycle reactive dyes. Sep Purif Technol 275:119236

3. Foroutan R, Peighambardoust SJ, Peighambardoust SH, et al (2021) Adsorption of Crystal Violet Dye Using Activated Carbon of Lemon Wood and Activated Carbon/Fe3O4 Magnetic Nanocomposite from Aqueous Solutions: A Kinetic, Equilibrium and Thermodynamic Study. Mol. 26

4. Prajapati AK, Mondal MK (2020) Comprehensive kinetic and mass transfer modeling for methylene blue dye adsorption onto $\mathrm{CuO}$ nanoparticles loaded on nanoporous activated carbon prepared from waste coconut shell. J Mol Liq 307:112949

5. Pashaei-Fakhri S, Peighambardoust SJ, Foroutan R, et al (2021) Crystal violet dye sorption over acrylamide/graphene oxide bonded sodium alginate nanocomposite hydrogel. Chemosphere 270:129419. https://doi.org/https://doi.org/10.1016/j.chemosphere.2020.129419

6. Elwakeel KZ, Elgarahy AM, Guibal E (2021) A biogenic tunable sorbent produced from upcycling of aquatic biota-based materials functionalized with methylene blue dye for the removal of chromium (VI) ions. J Environ Chem Eng 9:104767

7. Boushehrian MM, Esmaeili H, Foroutan R (2020) Ultrasonic assisted synthesis of Kaolin/CuFe2O4 nanocomposite for removing cationic dyes from aqueous media. J Environ Chem Eng 8:103869

8. Mittal H, Al Alili A, Morajkar PP, Alhassan SM (2021) Graphene oxide crosslinked hydrogel nanocomposites of xanthan gum for the adsorption of crystal violet dye. J Mol Liq 323:115034. https://doi.org/https://doi.org/10.1016/j.molliq.2020.115034

9. Soni S, Bajpai PK, Mittal J, Arora C (2020) Utilisation of cobalt doped Iron based MOF for enhanced removal and recovery of methylene blue dye from waste water. J Mol Liq 314:113642

10. Foroutan R, Mohammadi R, MousaKhanloo F, et al (2020) Performance of montmorillonite/graphene oxide/CoFe2O4 as a magnetic and recyclable nanocomposite for cleaning methyl violet dye-laden wastewater. Adv Powder Technol 31:3993-4004. https://doi.org/https://doi.org/10.1016/j.apt.2020.08.001

11. Esvandi Z, Foroutan R, Peighambardoust SJ, et al (2020) Uptake of anionic and cationic dyes from water using natural clay and clay/starch/MnFe2O4 magnetic nanocomposite. Surfaces and Interfaces 21:100754. https://doi.org/https://doi.org/10.1016/j.surfin.2020.100754

12. Iqbal MM, Imran M, Hussain T, et al (2021) Effective sequestration of Congo red dye with $\mathrm{ZnO} /$ cotton stalks biochar nanocomposite: MODELING, reusability and stability. J Saudi Chem Soc 25:101176

13. Abdolhosseinzadeh M, Peighambardoust SJ, Erfan-Niya H, Pakdel PM (2018) Swelling and auramine-O adsorption of carboxymethyl cellulose grafted poly (methyl methacrylate)/Cloisite 30B nanocomposite hydrogels. Iran Polym J 27:807-818

14. Pereira AGB, Rodrigues FHA, Paulino AT, et al (2021) Recent advances on composite hydrogels 
designed for the remediation of dye-contaminated water and wastewater: A review. J Clean Prod 284:124703

15. da Costa JS, Bertizzolo EG, Bianchini D, Fajardo AR (2021) Adsorption of benzene and toluene from aqueous solution using a composite hydrogel of alginate-grafted with mesoporous silica. $\mathrm{J}$ Hazard Mater 418:126405

16. Jamali M, Akbari A (2021) Facile fabrication of magnetic chitosan hydrogel beads and modified by interfacial polymerization method and study of adsorption of cationic/anionic dyes from aqueous solution. J Environ Chem Eng 9:105175

17. Ravash N, Peighambardoust SH, Soltanzadeh M, et al (2020) Impact of high-pressure treatment on casein micelles, whey proteins, fat globules and enzymes activity in dairy products: a review. Crit Rev Food Sci Nutr 1-21. https://doi.org/10.1080/10408398.2020.1860899

18. Chaudhary J, Thakur S, Mamba G, et al (2021) Hydrogel of gelatin in the presence of graphite for the adsorption of dye: Towards the concept for water purification. J Environ Chem Eng 9:104762

19. Panic V V, Velickovic SJ (2014) Removal of model cationic dye by adsorption onto poly (methacrylic acid)/zeolite hydrogel composites: kinetics, equilibrium study and image analysis. Sep Purif Technol 122:384-394

20. Peighambardoust SH, Hamer RJ, Boom RM, van der Goot AJ (2008) Migration of gluten under shear flow as a novel mechanism for separating wheat flour into gluten and starch. J Cereal Sci 48:327-338. https://doi.org/10.1016/j.jcs.2007.10.005

21. Soltanzadeh M, Peighambardoust SH, Ghanbarzadeh B, et al (2021) Chitosan Nanoparticles as a Promising Nanomaterial for Encapsulation of Pomegranate (Punica granatum L.) Peel Extract as a Natural Source of Antioxidants. Nanomater. 11

22. Tao E, Ma D, Yang S, Hao X (2020) Graphene oxide-montmorillonite/sodium alginate aerogel beads for selective adsorption of methylene blue in wastewater. J Alloys Compd 832:154833

23. Cheira MF, Kouraim MN, Zidan IH, et al (2020) Adsorption of U (VI) from sulfate solution using montmorillonite/polyamide and nano-titanium oxide/polyamide nanocomposites. J Environ Chem Eng 8:104427

24. Foroutan R, Peighambardoust SJ, Latifi P, et al (2021) Carbon nanotubes/ $\beta$ cyclodextrin/MnFe2O4 as a magnetic nanocomposite powder for tetracycline antibiotic decontamination from different aqueous environments. J Environ Chem Eng 106344

25. Esmaeili H, Foroutan R (2018) Adsorptive behavior of methylene blue onto sawdust of sour lemon, date palm, and eucalyptus as agricultural wastes. J Dispers Sci Technol

26. Nanda R, Sasmal A, Nayak PL (2011) Preparation and characterization of chitosan-polylactide composites blended with Cloisite 30B for control release of the anticancer drug paclitaxel. Carbohydr Polym 83:988-994

27. Paci M, Filippi S, Magagnini P (2010) Nanostructure development in nylon 6-Cloisite ${ }^{\circledR} 30 B$ composites. Effects of the preparation conditions. Eur Polym J 46:838-853

28. Soltanzadeh M, Peighambardoust SH, Ghanbarzadeh B, et al (2021) Chitosan nanoparticles encapsulating lemongrass (Cymbopogon commutatus) essential oil: Physicochemical, structural, antimicrobial and in-vitro release properties. Int J Biol Macromol 192:1084-1097. https://doi.org/10.1016/J.IJBIOMAC.2021.10.070 
29. Teimouri A, Esmaeili H, Foroutan R, Ramavandi B (2018) Adsorptive performance of calcined Cardita bicolor for attenuating $\mathrm{Hg}$ (II) and As (III) from synthetic and real wastewaters. Korean J Chem Eng 35:479-488

30. Zhang Y, Yin M, Sun X, Zhao J (2020) Implication for adsorption and degradation of dyes by humic acid: Light driven of environmentally persistent free radicals to activate reactive oxygen species. Bioresour Technol 307:123183

31. Peighambardoust SH, van Brenk S, van der Goot AJ, et al (2007) Dough processing in a Couettetype device with varying eccentricity: Effect on glutenin macro-polymer properties and dough micro-structure. J Cereal Sci 45:34-48. https://doi.org/10.1016/j.jcs.2006.05.009

32. van der Goot AJJ, Peighambardoust SHH, Akkermans C, Van Oosten-Manski JMM (2008) Creating novel structures in food materials: The role of well-defined shear flow. Food Biophys 3:120-125. https://doi.org/10.1007/s11483-008-9081-8

33. Baidya KS, Kumar U (2021) Adsorption of brilliant green dye from aqueous solution onto chemically modified areca nut husk. South African J Chem Eng 35:33-43

34. Esvandi Z, Foroutan R, Mirjalili M, et al (2019) Physicochemical Behavior of Penaeuse semisulcatuse Chitin for $\mathrm{Pb}$ and $\mathrm{Cd}$ Removal from Aqueous Environment. J Polym Environ 27:263-274. https://doi.org/10.1007/s10924-018-1345-x

35. Foroutan $\mathrm{R}$, Mohammadi $\mathrm{R}$, Ahmadi A, et al (2022) Impact of $\mathrm{ZnO}$ and $\mathrm{Fe} 3 \mathrm{O} 4$ magnetic nanoscale on the methyl violet 2B removal efficiency of the activated carbon oak wood. Chemosphere 286:131632

36. Adel M, Ahmed MA, Mohamed AA (2021) Synthesis and characterization of magnetically separable and recyclable crumbled $\mathrm{MgFe} 2 \mathrm{O} 4 /$ reduced graphene oxide nanoparticles for removal of methylene blue dye from aqueous solutions. J Phys Chem Solids 149:109760

37. Pelalak R, Heidari Z, Khatami SM, et al (2021) Oak wood ash/GO/Fe3O4 adsorption efficiencies for cadmium and lead removal from aqueous solution: Kinetics, equilibrium and thermodynamic evaluation. Arab J Chem 14:102991

38. Rao MM, Ramana DK, Seshaiah K, et al (2009) Removal of some metal ions by activated carbon prepared from Phaseolus aureus hulls. J Hazard Mater 166:1006-1013

39. Dash RR, Balomajumder C, Kumar A (2009) Removal of cyanide from water and wastewater using granular activated carbon. Chem Eng J 146:408-413

40. Foroutan R, Peighambardoust SJ, Hemmati S, et al (2021) Zn 2+ removal from the aqueous environment using a polydopamine/hydroxyapatite/Fe $3 \mathrm{O} 4$ magnetic composite under ultrasonic waves. RSC Adv 11:27309-27321

41. Foroutan R, Peighambardoust SJ, Esvandi Z, et al (2021) Evaluation of two cationic dyes removal from aqueous environments using $\mathrm{CNT} / \mathrm{MgO} / \mathrm{CuFe} 2 \mathrm{O} 4$ magnetic composite powder: $\mathrm{A}$ comparative study. J Environ Chem Eng 9:104752. https://doi.org/https://doi.org/10.1016/j.jece.2020.104752

42. Nithya R, Gomathi T, Sudha PN, et al (2016) Removal of Cr (VI) from aqueous solution using chitosan-g-poly (butyl acrylate)/silica gel nanocomposite. Int J Biol Macromol 87:545-554

43. Vitela-Rodriguez AV, Rangel-Mendez JR (2013) Arsenic removal by modified activated carbons with iron hydro (oxide) nanoparticles. J Environ Manage 114:225-231 
44. Foroutan R, Mohammadi R, Farjadfard S, et al (2019) Eggshell nano-particle potential for methyl violet and mercury ion removal: Surface study and field application. Adv Powder Technol 30:2188-2199. https://doi.org/https://doi.org/10.1016/j.apt.2019.06.034

45. Shen T, Luo J, Zhang S, Luo X (2015) Hierarchically mesostructured MIL-101 metal-organic frameworks with different mineralizing agents for adsorptive removal of methyl orange and methylene blue from aqueous solution. J Environ Chem Eng 3:1372-1383

46. Bulut Y, Aydin H (2006) A kinetics and thermodynamics study of methylene blue adsorption on wheat shells. Desalination 194:259-267

47. Peighambardoust SH, van der Goot AJ, Boom RM, Hamer RJ (2006) Mixing behaviour of a zerodeveloped dough compared to a flour-water mixture. J Cereal Sci 44:12-20. https://doi.org/10.1016/j.jcs.2005.12.011

48. Liu C, Omer AM, Ouyang X (2018) Adsorptive removal of cationic methylene blue dye using carboxymethyl cellulose/k-carrageenan/activated montmorillonite composite beads: Isotherm and kinetic studies. Int J Biol Macromol 106:823-833

49. Khodaeimehr R, Peighambardoust SJ, Peighambardoust SH (2018) Preparation and Characterization of Corn Starch/Clay Nanocomposite Films: Effect of Clay Content and Surface Modification. Starch/Staerke. https://doi.org/10.1002/star.201700251

50. Taşdelen B, Çifçi Dİ, Meriç S (2017) Preparation of N-isopropylacrylamide/itaconic acid/Pumice highly swollen composite hydrogels to explore their removal capacity of methylene blue. Colloids Surfaces A Physicochem Eng Asp 519:245-253

51. Coşkun R, Delibaş A (2012) Removal of methylene blue from aqueous solutions by poly (2acrylamido-2-methylpropane sulfonic acid-co-itaconic acid) hydrogels. Polym Bull 68:1889-1903

52. Hu X-S, Liang R, Sun G (2018) Super-adsorbent hydrogel for removal of methylene blue dye from aqueous solution. J Mater Chem A 6:17612-17624

53. Foroutan R, Peighambardoust SJ, Hosseini SS, et al (2021) Hydroxyapatite biomaterial production from chicken (femur and beak) and fishbone waste through a chemical less method for $\mathrm{Cd} 2+$ removal from shipbuilding wastewater. J Hazard Mater 413:125428. https://doi.org/https://doi.org/10.1016/j.jhazmat.2021.125428 